\title{
The Effect of Silane Treated Sugar Cane Bagasse on Mechanical, Thermal and Crystallization Studies of Recycled Polypropylene
}

\author{
Tshwafo E. Motaung1*, Linda Z. Linganiso1,2, Maya John1,2, Rajesh D. Anandjiwala1,2 \\ ${ }^{1}$ CSIR Materials Science and Manufacturing, Polymers and Composites Competence Area, Nonwovens and \\ Composites Research Group, Port Elizabeth, South Africa \\ ${ }^{2}$ Department of Textile Science, Faculty of Science, Nelson Mandela Metropolitan University, Port Elizabeth, \\ South Africa \\ Email: ${ }^{\text {TEMotaung@csir.co.za }}$
}

Received 10 April 2015; accepted 31 July 2015; published 5 August 2015

Copyright (C) 2015 by authors and Scientific Research Publishing Inc.

This work is licensed under the Creative Commons Attribution International License (CC BY).

http://creativecommons.org/licenses/by/4.0/

(c) (†) Open Access

\begin{abstract}
This article describes the results of an investigation on the influence of loading silane treated sugar cane bagasse (SB) on the morphology and properties of recycled polypropylene (rPP). The samples are prepared through melt extrusion followed by injection moulding. The Scanning electron microscopy (SEM), Fourier transform infrared spectroscopy (FTIR), X-ray diffraction (XRD) results show that SB-rPP composites have a fairly strong interfacial interaction and a change in crystallization for the highest containing SB composite, however, some fibre pull-outs are observed as the SB content is increased. The interaction influences the thermal and mechanical properties of the samples in a complex way. There are strong indications of a stronger interfacial interaction on the highest containing SB composite, which is supposedly accountable for the increased crystallinity and melting temperature.
\end{abstract}

\section{Keywords}

Sugar Cane Bagasse, Silane Treatment, Polypropylene Composites

\section{Introduction}

Interest in composite materials reinforced with natural fibres has recently increased considerably due to some natural benefits of the fibres. These materials present low cost, low density, high specific properties and are

${ }^{*}$ Corresponding author.

How to cite this paper: Motaung, T.E., Linganiso, L.Z., John, M. and Anandjiwala, R.D. (2015) The Effect of Silane Treated Sugar Cane Bagasse on Mechanical, Thermal and Crystallization Studies of Recycled Polypropylene. Materials Sciences and Applications, 6, 724-733. http://dx.doi.org/10.4236/msa.2015.68074 
biodegradable [1]-[4]. Other necessary properties related to processing include lower equipment abrasion and lower energy consumption. For these reasons natural fibres reinforced polymers have dominated applications such as furniture, architectural materials and lately in automotive industry in commercial marketplaces [5]-[7]. Subsequently, natural fibers, such as sisal, banana, wood, jute, kenaf, hemp, pineapple and rice husk, have been successfully used to improve the mechanical properties of plastic composites [8] [9]. Amongst all the materials, sugar cane bagasse has been receiving attention in the world lately due to large availability and rate of production, which is roughly $1.7 \times 10^{3}$ tons/year. Brazil was recorded as the latest largest producer of sugar cane with 635 million tons in 2011, of which 27.6\% (175 million tons) was converted into sugar cane bagasse [10]. The low economic value of sugar cane bagasse had encouraged to be applied mainly for fuel in order to produce energy, contributing to the greenhouse effect. Of late, studies have reported the use of sugar cane bagasse fibers as filler in thermoplastic composite, in which composites with different mechanical properties were developed [11]-[14].

Neto et al. [15] used sugar cane bagasse as a filler in composites having recycled high-density polyethylene (PEr) as matrix. Because of the poor interaction between fibers surface and the PEr, the surface of bagasse was chemically modified. The modification consisted of washing with water at $80^{\circ} \mathrm{C}$, a mercerization process using sodium hydroxide and acetylation reaction with acetic anhydride. Morphological analysis indicated that the chemical modification of sugar cane bagasse increased the compatibility between matrix and reinforcement. Tensile, flexural, and impact tests showed that the mechanical properties of the composite were improved due to the presence of the fibers. The similar observations were found in the study of Huang et al. [16]. The latter studied the properties of sugar cane bagasse/poly(vinyl chloride) (PVC) composites. Sugar cane bagasse (SB) was pre-treated by mechanical activation (MA) using a self-designed stirring ball mill and a surface modification by using aluminate coupling agent (ACA). Both untreated and treated SBs were used to produce composites with PVC as polymer matrix. SB showed that MA enhanced the condensation reaction between ACA and hydroxyl groups of the SB fibres, which increased the hydrophobicity of SB. The mechanical properties of both the PVC composites reinforced by SB with and without ACA modification increased with increasing milling time. They attributed the increase to the improved interfacial adhesion and a better dispersion of SB. Wang et al. [17] studied green composites of Poly (Lactic Acid) and sugar cane bagasse residues. Twin-screw extrusion was used to prepare the composites consisting of PLA and three types of sugar cane bagasse residues (up to 30 wt.\%) derived from different steps of a biorefinery process. Each residue had different composition, particle size and surface reactivity due to chemical and biological (enzyme, microbes) treatments that the biomass was subjected to. The effects of different residue characteristics on properties, crystallization behaviours and morphologies of PLA composites were investigated in the presence of a $2 \%$ coupling agent. The results indicated that in the presence of the $2 \%$ coupling agent improved mechanical properties of PLA composite, while PLA composite with fermentation residue exhibited the minimum strength properties.

Nonetheless, the greatest drawback to the utilization of natural fibers is related to matrix/filler adhesion due to the fact that natural fibers are hydrophilic and the polymeric matrix is hydrophobic, yielding composites with poor mechanical properties. In order to overcome the problem, many papers have reported that the modification of fibers surface increases the compatibility between the matrix and the reinforcement. In fact, most of these publications have used the same treatments, which are alkaline, acetylation and bleaching [18] [19]. The following work will give more information about mechanical and thermal properties of silane treated sugar bagasse-recycled polymer composites.

One of the important commonly applied commercial polymer that received a minimum attention as a matrix of sugar bagasse filler is polypropylene (PP). PP is widely used in packaging and in a variety of other applications due to their great potential in terms of barrier properties, brilliance, dimensional stability and processability. As the use of the material widens, the waste disposed of into the environment also escalates. It is for that reason recycled PP (rPP) is used in this study. Besides, rPP has higher biodegradation rate compared to PP [20].

\section{Experiments}

\subsection{Materials}

SB was supplied by a farm in Craddock near Port Elizabeth, South Africa. 3-aminopropyl tri-ethoxysilane was purchased from Sigma Aldrich, South Africa. All chemicals were used as received without further purification. 


\subsection{Methods}

\subsubsection{Silane Treatment of Sugar Bagasse}

1\% solution 3-aminopropyl tri-ethoxysilane (A1100) was prepared by mixing the silane with an ethanol/water mixture in the ratio 6/4. The $\mathrm{pH}$ of the solution was adjusted to 4 with acetic acid. The SB was soaked in the solution and allowed to stand for 2 hours. The silane solution was drained out and the fibres were washed with distilled water. Finally the SB was dried in an oven at $70^{\circ} \mathrm{C}$ until completely dry.

\subsubsection{Extrusion of rPP with SB Fibres}

A co-rotating twin-screw extruder (CTE-20, Coperion, China) equipped with a main feeder and side feeder as well as a strand pelletizer with an L/D ratio of 40 was employed to compound the rPP and SB. SB and rPP were dried in a convection oven at $40^{\circ} \mathrm{C}$ for $24 \mathrm{~h}$ before extrusion. The temperature profile during extrusion was set from $160^{\circ} \mathrm{C}-170^{\circ} \mathrm{C}$ and screw speed was maintained at $40 \mathrm{rpm}$.

\subsubsection{Preparation of Composites}

BOY 22M (Germany) injection moulding machine was used to form dumbbell of rPP/SB composites.

\subsection{Characterization}

\subsubsection{Fourier Transform Infrared Spectroscopy (FTIR)}

FTIR of the samples were carried out on a Spectrum 100 FTIR (Perkin Elmer, Waltham, MA, USA). The range used was between 500 and $4000 \mathrm{~cm}^{-1}$.

\subsubsection{X-Ray Diffraction Analysis (XRD)}

XRD patterns of the samples were recorded using Philips PW 1830 X-ray diffractometer with $\mathrm{Cu} \mathrm{K} \alpha$ radiation $(\lambda=0.154 \mathrm{~nm})$. The crystallinity index (CI) was determined by using XRD deconvolution method.

\subsubsection{Thermogravimetric Analysis (TGA)}

Thermogravimetric analysis was carried out with a Perkin Elmer Pyris 1 TGA. The analyses were done under flowing nitrogen at a constant flow rate of $20 \mathrm{~mL} \cdot \mathrm{min}^{-1}$. The samples $(5-10 \mathrm{mg})$ were heated from $25^{\circ} \mathrm{C}-$ $600^{\circ} \mathrm{C}$ at a heating rate $10^{\circ} \mathrm{C} \cdot \mathrm{min}^{-1}$.

\subsubsection{Differential Scanning Calorimetry}

The DSC analyses were performed on a Perkin Elmer Pyris-1 differential scanning calorimeter (Waltham, Massachusetts, USA). The analyses were performed under flowing nitrogen $\left(20 \mathrm{~mL} \cdot \mathrm{min}^{-1}\right)$. The instrument was calibrated using the onset temperatures of melting of indium and zinc standards, as well as the melting enthalpy of indium. 5 - $10 \mathrm{mg}$ samples were sealed in aluminium pans, heated from $0^{\circ} \mathrm{C}$ to $160^{\circ} \mathrm{C}$ at a heating rate of $10^{\circ} \mathrm{C} \cdot \mathrm{min}^{-1}$, and cooled at the same rate to $0^{\circ} \mathrm{C}$. For the second scan, the samples were heated and cooled under the same conditions. The onset and peak temperatures of melting as well as crystallization enthalpies were determined from the second scan. At least three different samples from each composite were analysed, and the average and standard deviation values for each property were calculated.

\subsubsection{Mechanical Properties}

The tensile strength of the composite samples were measured according to ASTM methods D882 (E) using an Instron model 3369 testing machine (Instron, Morwood, Massachusetts, USA) at a strain rate of $10 \mathrm{~mm} \cdot \mathrm{min}^{-1}$.

\section{Results and Discussion}

\subsection{Scanning Electron Microscopy (SEM)}

Figure 1 shows the fractured SEM images of the composites with different sugar cane bagasse contents at 100 and $50 \mu \mathrm{m}$ in alphabetical order of each sample. It is possible to see the isolation of fibre in the 5\% SB composites and a trapped broken fibre by rPP matrix at interface (Figure 1(A) and Figure 1(B)), which suggests that the SB is well dispersed in rPP matrix with a strong interaction at interface. The 15\% SB (Figure 1(C) and Figure 1(D)) composite indicated more fibre ends trapped into the rPP matrix. However, there are some of fibre 

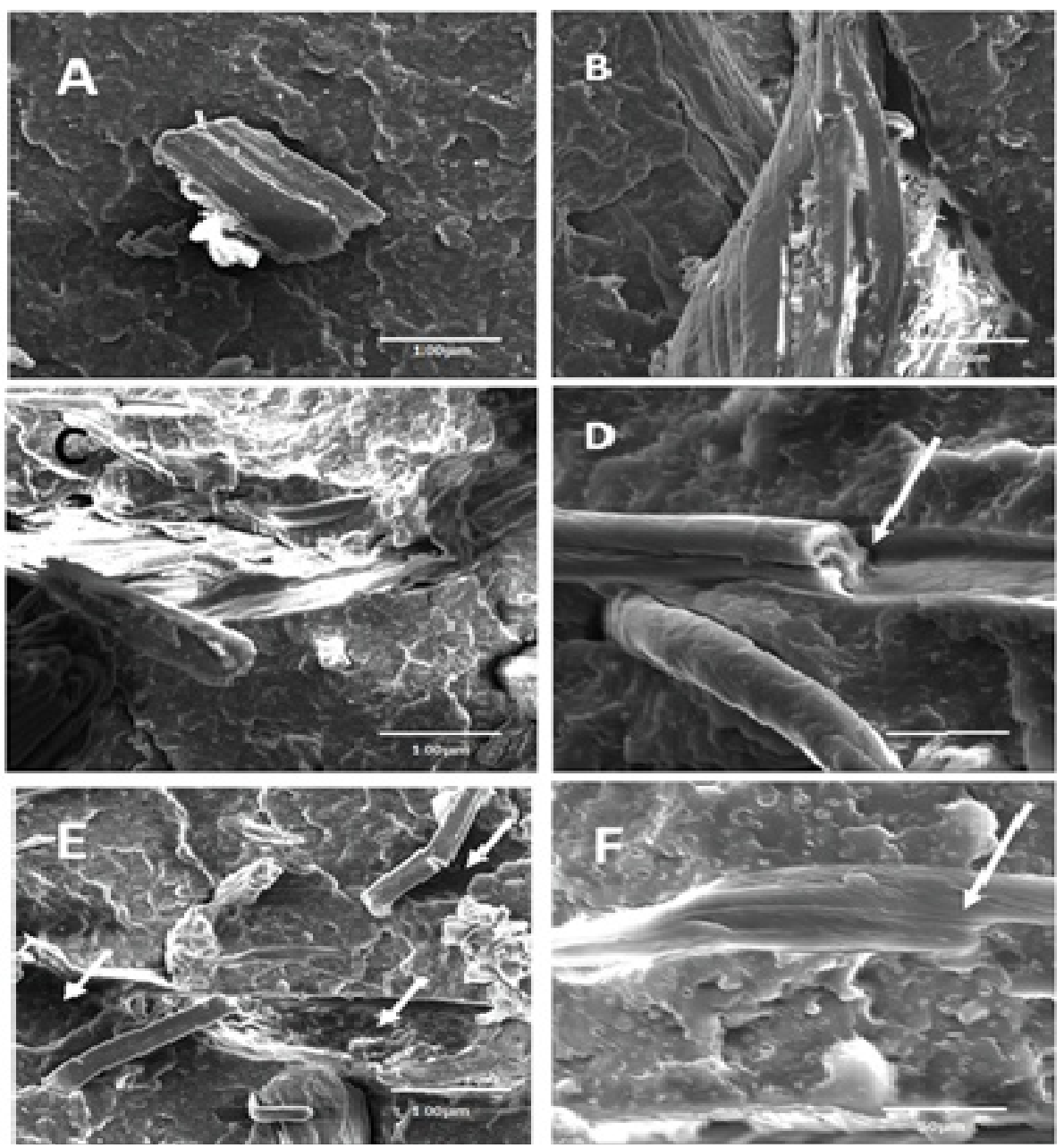

Figure 1. SEM images of the fractured surface of rPP composites.

pull-outs and breakage of fibres. More fibre ends appeared in the highest SB containing composites (indicated by the arrows) with the larger fibre pull-outs, although some remained trapped in rPP. The pull-outs in both $15 \%$ and 25\% SB (Figure 1(E) and Figure 1(F)), containing composites occurred adjacent to a trapped fibre, which suggests that fibre-fibre poor interaction is likely responsible for pull-outs over the rPP-SB interaction.

\subsection{X-ray Diffraction (XRD)}

Figure 2 shows XRD patterns of rPP and SB-rPP composites. Table 1 summarizes the crystallinity index values calculated by using Equation (1).

$$
X_{X R D}=\frac{\Sigma A_{\text {cryst }}}{\Sigma A_{\text {cryst }}+\Sigma A_{\text {amorp }}}
$$

where $A_{\text {cryst }}$ and $A_{\text {amorp }}$ are the fitted areas of the crystal and amorphous domains, respectively.

Pure rPP showed well known prominent peaks in the $2 \theta$ range of 15 - 30, which correspond to monoclinic $\alpha$-crystalline phase [21]. In the case of composites same numbers of peaks are observed in the same range, which suggest that these contained mainly $\alpha$-crystalline phase. However, the difference lies in the relatives' intensities of the reflection peaks. There is a general decrease in intensities with the addition of SB, further more (130) and (131) reflection peaks become broader in the presence of SB. In fact, Table 1 suggests that the difference in intensities could emanate from a reduced crystallinity of rPP. In contrast, the spectrum of SB-rPP 25 wt.\% indicated a new peak at $2 \theta$ around 16 and improved intensities of (110) and (040) reflection peaks. The similar 


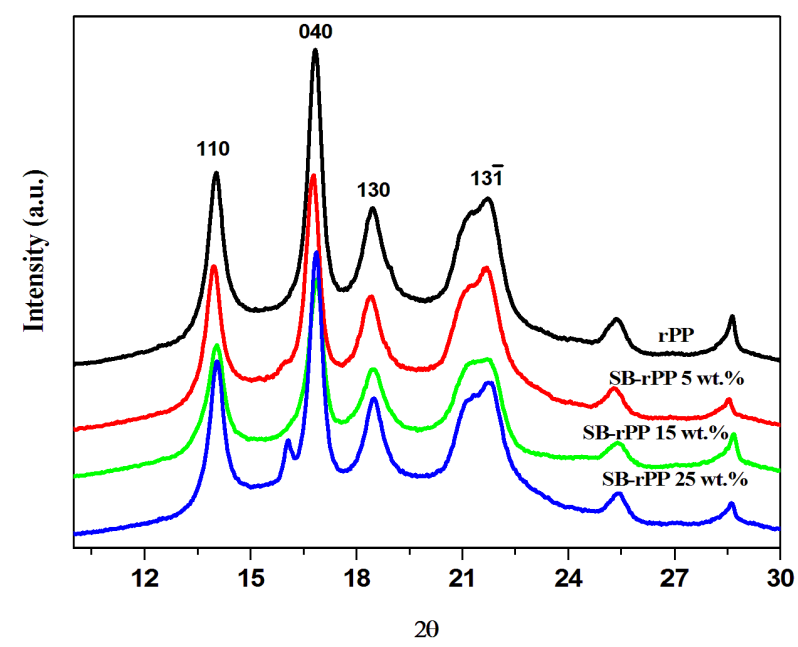

Figure 2. X-Ray diffraction profiles of rPP and SB-rPP composites.

Table 1. Summary of crystalline index values by deconvolution method.

\begin{tabular}{cccc}
\hline Sample & Ac & At & CI (\%) \\
\hline rPP & 44,451 & 98,939 & 31 \\
SB-rPP 5 wt.\% & 37,115 & 111,345 & 25 \\
SB-rPP 15 wt.\% & 37,040 & 157,907 & 19 \\
SB-rPP 25 wt.\% & 32,616 & 83,869 & 28 \\
\hline
\end{tabular}

results were observed by Mi et al. [22] and Motsoeneng et al. [23]. The former examined crystallization and interfacial morphology of bamboo fiber-reinforced PP, while the latter studied the effect of doping different nucleating agents on crystalline phase of impact polypropylene. Both studies attributed the observation to a considerable increase in amount of $\beta$-crystal formation produced in the PP. That could be the case in our results, possibly at $25 \%$ SB the more of silanol linkages interacted strongly with rPP and ultimately the polymer chain segments undergone transcrystallization process which favoured $\beta$-crystals growth.

\subsection{Fourier Transform Infrared Spectroscopy (FTIR)}

Figure 3 shows FTIR spectra of rPP and rPP-composites. As it was expected, all the spectra showed typical peaks of PP [24]. For instance, large four peaks in wave number range $3000-2800 \mathrm{~cm}^{-1}$ represent $\mathrm{CH}_{3}$ asymmetric, $\mathrm{CH}_{3}$ symmetric stretching, $\mathrm{CH}_{2}$ asymmetric and symmetric stretching vibrations respectively. While those at 1102, 1222 and $1258 \mathrm{~cm}^{-1}$ caused by $\mathrm{C}-\mathrm{C}$ asymmetric stretching, $\mathrm{C}-\mathrm{H}$ wagging and $\mathrm{CH}_{3}$ asymmetric deformation vibrations respectively.

The addition of SB decreased the intensities of most peaks, more evident from approximately 800 to 1100 $\mathrm{cm}^{-1}$, and an appearance of new peak at $1022 \mathrm{~cm}^{-1}$. Some of the peaks from the spectrum of SB-rPP $25 \mathrm{wt} . \%$ in the range are either not observed or much less intense. The decreased intensities could be due to the reorientation of polymeric chains as the results of interaction with SB fibres, whereas the significant intensity reduction in SB-rPP 25 wt.\% spectrum could either be attributed to a change in crystal structure observed in XRD and/or a strong interfacial adhesion. The appearance of the new peak could results from the interfacial interaction between rPP and siloxane bridges of the natural fibres [25].

\subsection{Thermogravimetric Analysis (TGA)}

Figure 4 shows the thermal degradation and derivatives curves (DTG) of the investigated samples. The TGA curves of the composites indicate two decomposition steps for all samples with the magnitude of the first step 


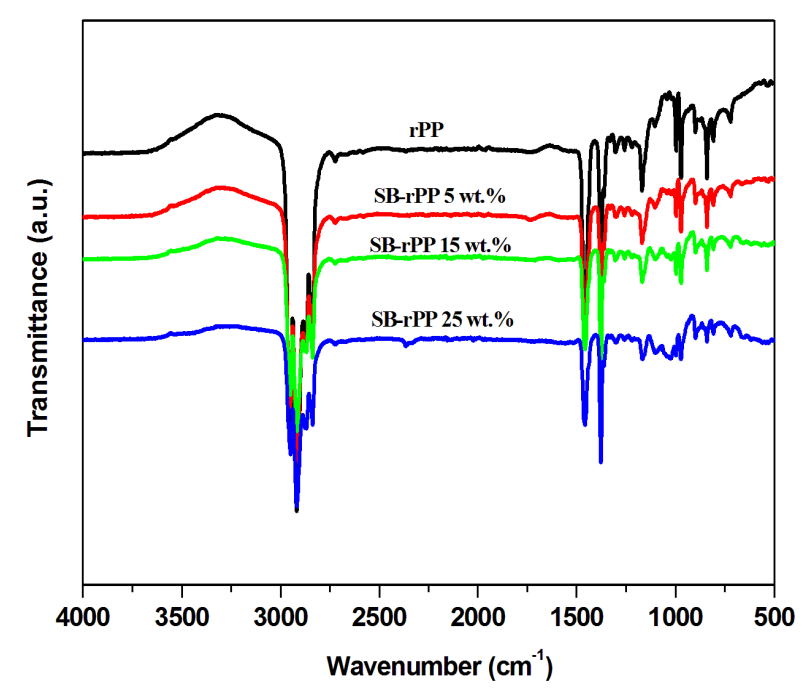

Figure 3. FTIR spectra of the of rPP and composites.
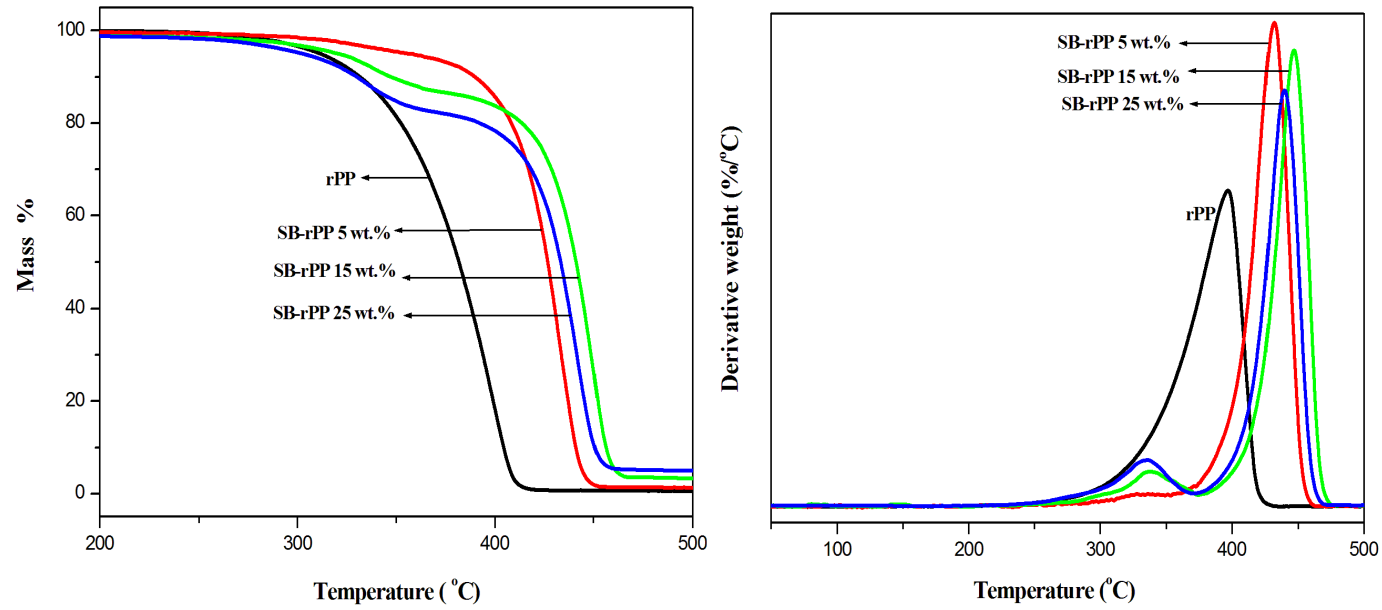

Figure 4. TGA and DTG curves of rPP and the SB-rPP composites.

closer to the amount of sugar cane bagasse. That is confirmed by well resolved DTG's first and second peaks around $340^{\circ} \mathrm{C}$ and above $400^{\circ} \mathrm{C}$ respectively. The two decomposition steps could, therefore, be attributed to the sugar cane bagasse and matrix decompositions respectively. The addition of SB significantly increased the thermal stability by approximately $50^{\circ} \mathrm{C}$ difference compared to the pure rPP. This is further indicated in DTG by the shift of the major peaks, attributed to rPP degradation, to higher temperatures. Contrary to our trend, some researchers observed a decrease in thermal stability of SB-PP composites and related the observations to lower thermal decomposition temperatures of SB and moisture content [7] [26]. In our case, the silane functionalization probably formed siloxane bridges between the natural fibres and rPP as indicated by literature [25]. As a result, the bridges altered the interfacial chemistry of SB and rPP to yield thermally stable intermediates during the degradation. Possibly more of siloxane bridges were formed with an increase in SB content, and enhanced the interfacial interaction which favored higher thermal stability. The results complement SEM which indicated a strong rPP-fibre interaction throughout the SB contents and pull-outs at an adjacent fiber. The highest containing SB composites appeared to be beyond a critical concentration of siloxane bridges which could account for the slight drop in the thermal stability.

\subsection{Differential Scanning Calorimetry (DSC)}

The DSC curves for the samples are shown in Figure 5 and the melting, degree of crystallinity and enthalpy 
characteristics are summarized in Table 2 . The degree of crystallinity, $\chi_{c}$, of samples was calculated according to the following equation:

$$
\chi_{c}=\frac{\Delta H_{m}}{\Delta H_{\infty}} \times \frac{100}{w}
$$

The melting enthalpy of $100 \%$ crystalline polymer, $\Delta H_{\infty}$, was taken as $207 \mathrm{~J} \cdot \mathrm{g}^{-1}$ for rPP [20].

A correction for diluting effect linked to the filler incorporation in the matrix was made when calculating the normalised melting enthalpy $\left(\Delta H_{m}^{\text {norm }}\right)$ of the composites, where $w$ is the weight fraction of the polymer matrix.

From Table 2 it can be seen that the melting temperature $\left(T_{m}\right)$ of rPP and all rPP composites was similar within experimental uncertainty (Table 2), except a slight increase in the highest containing sugar bagasse composite. The observed melting enthalpy, as expected, decreased with an increase in sugar cane bagasse content. This was the result of a decrease in the amount of polymer in the composites. The $\chi_{c}$ and normalized enthalpy values for the composites generally decreased with the SB content, except SB-rPP 25 wt.\% which indicated an increase. The decrease is normally attributed to an increase in elastomeric phase of the polymer in the presence of fibre. As for the increase in melting enthalpy and melting temperature of SB-rPP 25 wt.\%, the change in crystalline structure as confirmed by XRD and strong interaction at rPP-fibre interface as opposed by fibre-fibre interaction from SEM could account for the observations.

\subsection{Mechanical Properties}

The influence of sugar cane content on the modulus, stress and elongation at break of the different composites are shown in Figure 6. The composites show a linear increase in Young's modulus with an increase in SB con-

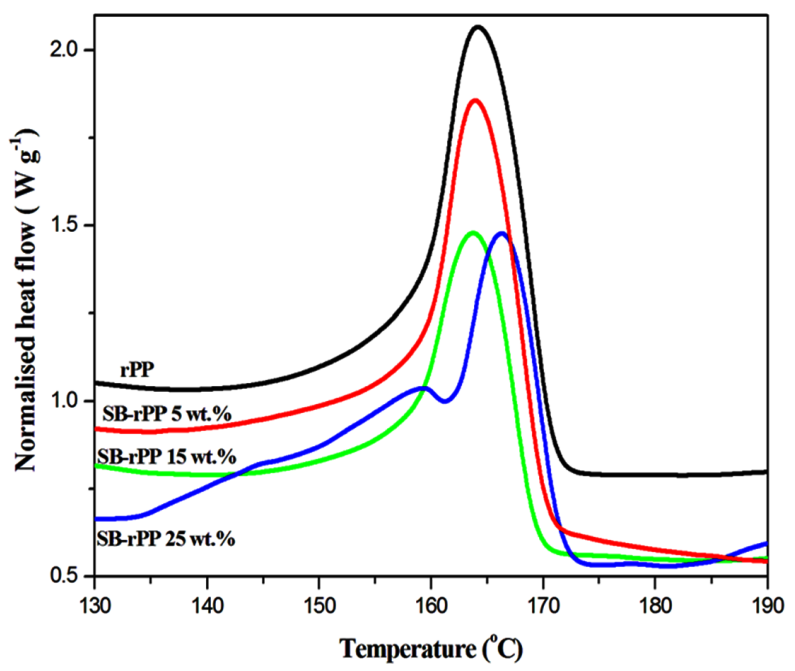

Figure 5. DSC of rPP composites.

Table 2. Summary of DSC melting and crystallization peak temperatures and enthalpies for all the investigated samples.

\begin{tabular}{|c|c|c|c|c|}
\hline \multirow{2}{*}{ Sample } & \multicolumn{4}{|c|}{ Second heating } \\
\hline & $\mathrm{T}_{\mathrm{p}, \mathrm{m}}\left({ }^{\circ} \mathrm{C}\right)$ & $\Delta H_{m}^{o b s} \quad\left(\mathrm{~J} \mathrm{~g}^{-1}\right)$ & $\Delta H_{m}^{\text {norm }}\left({\left.\mathrm{J} \cdot \mathrm{g}^{-1}\right)}^{-1}\right.$ & $\chi_{c} / \%$ \\
\hline $\mathrm{rPP}$ & $164.2 \pm 0.4$ & $80.0 \pm 1.3$ & 80 & 38.6 \\
\hline SB-rPP-5 wt.\% & $163.9 \pm 0.7$ & $66.9 \pm 1.5$ & 70.4 & 34 \\
\hline SB-rPP-15 wt.\% & $163.9 \pm 0.5$ & $52.5 \pm 1.7$ & 61.8 & 29.9 \\
\hline SB-rPP-25 wt.\% & $166.4 \pm 0.2$ & $48.4 \pm 0.2$ & 64.5 & 31.2 \\
\hline
\end{tabular}




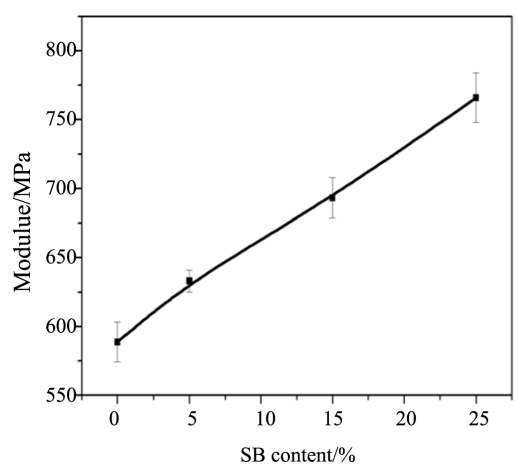

(a)

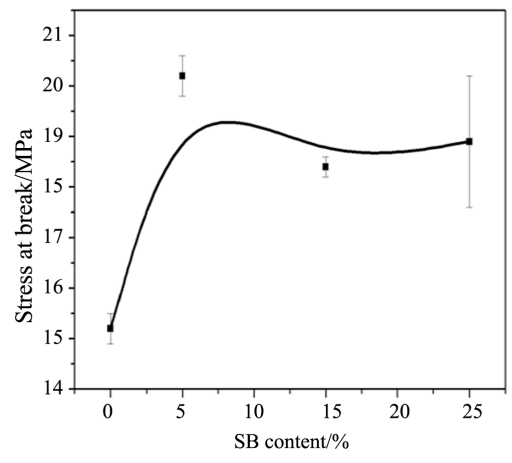

(b)

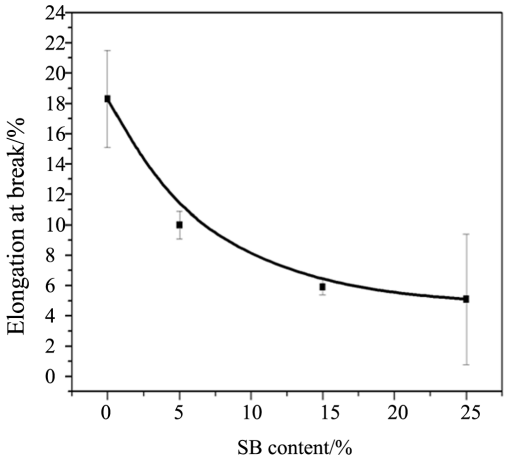

(c)

Figure 6. Young's modulus, stress and Elongation at break of rPP composites.

tent (Figure 6(a)). The increase in Young's modulus in the presence of a natural fibre is normally attributed to high modulus of the fibre compared to a thermoplastic matrix [4] [7] [8]. However, the persistent increase in modulus with an increase with the fibre content is rare in literature. In most cases modulus of sugar cane-thermoplastic composites drops at about 20 wt.\% regardless of a treatment [11]-[13]. The strong interaction between rPP and SBin the current study, as proven by SEM, FTIR and TGA, likely promoted stress transfer at the interface to increase moduli for all SB contents. Stress at break increased at the lowest SB content and slightly decreased to almost constant value with an increase in SB content (Figure 6(b)). The initial increase could be attributed to a dispersion of the fibre and a strong interfacial adhesion. Whereas clustering of fibre ends and the pull-outs may account for the observed decrease.

The elongation at break of all SB-rPP composites decreases with an increase in SB content, although the effect is less significant in the highest containing SB composite (Figure 6(c)). That may result from the presence of the SB in the polymer matrix which increased the number of defect points to initiate and propagate stress cracking in the polymer matrix. As a result, the material will lose its drawability and elongation at break will decrease. In addition, DSC indicated the decrease in crystallinity in the presence of SB, while XRD showed some changes in crystalline structure. It is therefore safe to assume that the changes in crystallinity and crystalline structure seem to have occurred at an expense of the loss in number of tie chains which lead to reduced elongation at break values.

\section{Conclusion}

Sugar cane bagasse-recycled polypropylene composites were successfully prepared by aninjection moulding technique. SEM analysis showed evidence of strong rPP-SB interface despite fibre pull-outs at higher SB contents. XRD results showed that the addition of SB decreased crystallinity and induced $\beta$-crystal growth in the highest SB containing composite. The $\beta$-crystal formation led to an improved crystallinity of the composite. FTIR analysis indicated that an addition of SB decreased intensities of most peaks and the observation was pronounced in the highest SB containing composite. The addition of SB improved thermal stability of all composites and the higher SB containing composite was the most thermally stable. The interaction of SB with the polymer led to the improved crystallinity, melting temperature and mechanical properties.

\section{Acknowledgements}

This paper forms part of a research project, “Greener Cities in South Africa”, funded by the Green Fund, an environmental finance mechanism implemented by the Development Bank of Southern Africa (DBSA) on behalf of the Department of Environmental Affairs (DEA) and CSIR. Opinions expressed and conclusions arrived at are those of the author and are not necessarily to be attributed to the Green Fund, DBSA or DEA.

\section{References}

[1] Mwaikambo, L.Y. and Ansell, M.P. (2001) Chemical Modification of Hemp, Sisal and Kapok Fibres by Alkalization. Journal of Applied Polymer Science, 84, 2222-2234. http://dx.doi.org/10.1002/app.10460 
[2] Rosa, M.F., Medeiros, E.S., Malmonge, J.A. Gregorski, K.S., Wood, D.F., Mattoso, L.H.C., Glenn, G., Orts, W.J. and Imam, S.H. (2010) Cellulose Nanowhiskers from Coconut Husk Fibers: Effect of Preparation Conditions on Their Thermal and Morphological Behavior. Carbohydrate Polymers, 81, 83-92. http://dx.doi.org/10.1016/j.carbpol.2010.01.059

[3] John, M.J. and Thomas, S. (2008) Biofibres and Biocomposites. Carbohydrate Polymers, 71, 343-364. http://dx.doi.org/10.1016/j.carbpol.2007.05.040

[4] White, N.M. and Ansell, M.P. (1983) Straw-Reinforced Polyester Composites. Journal of Materials Science, 18, 15491556. http://dx.doi.org/10.1007/BF01111977

[5] Gerrard, J. and Kandlikar, M. (2007) Is European End-of-Life Legislation Living up to Expections? Assessing the Impact of the ELV Directive on “Green” Innovation and Vehicle Recovery. Journal of Cleaner Production, 15, 17-27. http://dx.doi.org/10.1016/j.jclepro.2005.06.004

[6] Soden, J. and Stewart, G.F.J. (2010) Natural Composites with 3D Woven Reinforcement for New Applications Areas, Journal of Biobased Materials and Bioenergy, 4, 139-147. http://dx.doi.org/10.1166/jbmb.2010.1078

[7] Luz, S.M., Pires A.C. and Ferrão, P.M.C. (2010) Environmental Benefits of Substituting Talc by Sugarcane Bagasse Fibers as Reinforcement in Polypropylene Composites: Ecodesign and LCA as Strategy for Automotive Components, Resources, Conservation and Recycling, 54, 1135-1144. http://dx.doi.org/10.1016/j.resconrec.2010.03.009

[8] Jústiz-Smith, N.G., Virgo, G.J. and Buchanan, V.E. (2008) Potential of Jamaican Banana, Coconut Coir and Bagasse Fibres as Composite Materials. Materials Characterization, 59, 1273-1278. http://dx.doi.org/10.1016/j.matchar.2007.10.011

[9] Placketta, D., Andersen, T.L., Pedersen, W.B. and Nielsen, L. (2003) Biodegradable Composites Based on L-Polylactide and Jute Fibres. Composites Science and Technology, 63, 1287-1296. http://dx.doi.org/10.1016/S0266-3538(03)00100-3

[10] Hofsetz, K. and Silva, M.A. (2012) Brazilian Sugarcane Bagasse: Energy and Non-Energy Consumption. Biomass \& Bioenergy, 46, 564-573. http://dx.doi.org/10.1016/j.biombioe.2012.06.038

[11] Dweiri, R. and Azhari, C.H. (2004) Thermal and Flow Property-Morphology Relationship of Sugarcane Bagasse FibreFilled Polyamide 6 Blends. Journal of Applied Polymer Science, 92, 3744-3754. http://dx.doi.org/10.1002/app.20359

[12] Stael, G.C., Tavares M.I.B. and d'Almeida, J.R.M. (2001) Impact Behaviour of Sugarcane Bagasse Waste-EVA Composites. Polymer Testing, 20, 869-872. http://dx.doi.org/10.1016/S0142-9418(01)00014-9

[13] Youssef, H.A., Ismail, M.R., Ali, M.A.M. and Zahran, A.H. (2008) Effect of the Various Coupling Agents on the Mechanical and Physical Properties of Thermoplastic-Bagasse Fiber Composites. Polymer Composites, 29, 1057-1065. http://dx.doi.org/10.1002/pc.20473

[14] Cerqueira, E.F., Baptista C.A.R.P. and Mulinaria, D.R. (2011) Mechanical Behaviour of Polypropylene Reinforced Sugarcane Bagasse Fibers Composites. Procedia Engineering, 10, 2046-2051. http://dx.doi.org/10.1016/j.proeng.2011.04.339

[15] de Carvalho Neto, A.G.V., Ganzerli, T.A., Cardozo, A.L., Fávaro, S.L., Pereira, A.G.B., Girotto, E.M. and Radovanovic, E. (2014) Development of Composites Based on Recycled Polyethylene/Sugarcane Bagasse Fiber. Polymer Composites, 35, 768-774. http://dx.doi.org/10.1002/pc.22720

[16] Huang, Z., Wang, N., Zhang, Y., H. H., Luo, Y. (2012) Effect of Mechanical Activation Pretreatment on the Properties of Sugarcane Bagasse/Poly(vinyl chloride) Composites. Composites Part A: Applied Science and Manufacturing, 43, 114-120. http://dx.doi.org/10.1016/j.compositesa.2011.09.025

[17] Wang, L.T., Tong, Z.H., Ingram, L.O., Cheng, Q.Z. and Matthews, S. (2013) Green Composites of Poly (Lactic Acid) and Sugarcane Bagasse Residues from Bio-Refinery Processes. Journal of Polymers and the Environment, 21, 780-788. http://dx.doi.org/10.1007/s10924-013-0601-3

[18] Fávaro, S.L., Lopes, M.S., Neto, A.G.V.C., Santana, R.R. and Radovanovic, E. (2010) Chemical, Morphological, and Mechanical Analysis of Rice Husk/Post-Consumer Polyethylene Composites. Composites Part A: Applied Science and Manufacturing, 41, 154-160. http://dx.doi.org/10.1016/j.compositesa.2009.09.021

[19] Goulart, S.A.S., Oliveira, T.A., Teixeira, A., Miléo P.C. and Mulinari, D.R. (2011) Mechanical Behaviour of Polypropylene Reinforced Palm Fibers Composites. Procedia Engineering, 10, 2034-2039. http://dx.doi.org/10.1016/j.proeng.2011.04.337

[20] Longo, C., Savaris, M., Zeni, M., Brandalise, N.R. and Grisa, A.M.C. (2011) Degradation Study of Polypropylene (PP) and Bioriented Polypropylene (BOPP) in the Environment. Materials Research, 14, 442-448. http://dx.doi.org/10.1590/S1516-14392011005000080

[21] Saujanya, C. and Radhakrishnan, S. (2001) Structure Development and Crystallization Behaviour of PP/Nanoparticulate Composite. Polymer, 42, 6723-6731. http://dx.doi.org/10.1016/s0032-3861(01)00140-9 
[22] Mi, Y.L., Chen, X.Y. and Guo, Q.P. (1997) Bamboo Fiber-Reinforced Polypropylene Composites: Crystallization and Interfacial Morphology. Journal of Applied Polymer Science, 64, 1267-1273. http://dx.doi.org/10.1002/(SICI)1097-4628(19970516)64:7<1267::AID-APP4>3.0.CO;2-H

[23] Motsoeneng, T.S., Luyt, A.S. and van Reenen, A.J. (2014) Investigation of the Crystalline Phase Morphology of a $\beta$ Nucleated Impact Polypropylene Copolymer. Journal of Applied Polymer Science, 131, 1-9. http://dx.doi.org/10.1002/app.39923

[24] Morent, R., Geyter, N.D., Leys, C., Gengembre, L. and Payen, E. (2008) Comparison between XPS-and FTIR-Analysis of Plasma-Treated Polypropylene Film Surfaces. Surface and Interface Analysis, 40, 597-600. http://dx.doi.org/10.1002/sia.2619

[25] Kabir, M.M., Wang, H., Lau, K.T. and Cardona, F. (2012) Chemical Treatments on Plant-Based Natural Fibre Reinforced Polymer Composites: An Overview. Composites Part B: Engineering, 43, 2883-2892. http://dx.doi.org/10.1016/j.compositesb.2012.04.053

[26] Ramaraj, B. (2007) Mechanical and Thermal Properties of Polypropylene/Sugarcane Bagasse. Journal of Applied Polymer Science, 103, 3827-3832. http://dx.doi.org/10.1002/app.25333 